\title{
DEPRESSION MEASURED BY PHQ-9 IN KOSOVO DURING THE COVID-19 OUTBREAK: AN ONLINE SURVEY
}

\author{
Naim Fanaj ${ }^{1,2}$ \& Sevim Mustafa ${ }^{1}$ \\ ${ }^{1}$ Mental Health Center Prizren, Prizren, Kosovo \\ ${ }^{2}$ College of Medical Sciences Rezonanca, Prishtina, Kosovo
}

received: 20.11.2020;

revised: 8.1.2021;

accepted: 20.1.2021

\section{SUMMARY}

Background: There are reports from countries and in the scientific literature that COVID-19 affect also mental health worldwide. The aim of this study was to understand the level of depression as a result of the COVID-19 situation and possible associations with sociodemographic variables.

Subjects and methods: It's a cross-sectional study. The participants were 155 respondents recruited online in the period 27.04.2020 until 05.06.2020, who completed the Albanian version of PHQ-9.

Results: Mean score of depression resulted 10.94 (SD=9.22). 63\% of participants agreed that the situation has worsened their psychological state; $35.6 \%$ had a mild to severe form of depression and $18.7 \%$ had minimal symptoms. $13.4 \%$ of participants saw $i C B T$ as helpful, $16.8 \%$ a little while $65.8 \%$ wanted to try it. Significantly higher depression resulted for females and age-group 18 to 24 years. No significant differences by levels of education, marital status, employment, socio-economic status and by expectations regarding iCBT. Gender and perception of worsened psychological state showed predictive abilities for depression.

Conclusion: The situation with Covid-19 has increased depression levels especially among females and 18 to 24 years old and thus expectations for e-psychotherapy. Online treatments seem feasible solutions for outbreak times. Studies in future are needed to better scientifically elaborate these findings.

Key words: COVID-19 - depression - PHQ-9 - online - Kosovo

$* * * * *$

\section{INTRODUCTION}

The outbreak of COVID-19 is severely affecting physical health and lives. The COVID-19 pandemic has been spreading across Kosovo from March, too. There are reports from countries and in the scientific literature that COVID-19 affect also mental health worldwide. The WHO has also expressed its concern over the pandemic's mental health and psycho-social consequences (World Health Organization 2020). Holmes et al. (2020) think that this impact might be profound. Recent studies, addressing the impact of COVID-19 exhibit the highest levels of psychological distress, although results have varied across studies. Stress, anxiety and depression are among the variables found and measured. Measuring psychological distress in the general population of Italy during the COVID-19 pandemic Mazza et al (2020) showed an increased percentage of people with high and very high levels of distress compared to the European epidemiological statistics. Higher levels of anxiety, depression and trauma symptoms (but not dramatically) were reported compared to previous population studies, in UK (Shevlin et al. 2020). Also, one study suggest that the psychological well-being of the general Danish population is affected negatively by the COVID19 pandemic (Sønderskov et al. 2020). A recent KFF poll (Panchal et al. 2020), show that $45 \%$ of USA adults reported that their mental health has been negatively impacted due to virus. Now, we have also preliminary evidence from population surveys from China showing significantly elevated symptomatology levels in distres related to COVID-19 (Huang \& Zhao 2020, Qiu et al. 2020, Wang C. et al. 2020; Wang Y. et al. 2020).

Already the first studies show a level of depression in the general population during the Covid-19 outbreak. There are nine studies that have used PHQ-9 and one PHQ-2. Based on the cut-off of PHQ-9, 10 and above, the prevalence of depression has been from 17.3 to $31.6 \%$. Thus, Rossi et al. (2020) in 18147 Italians find $17.3 \%$; Ueda et al. (2020) in 1000 Japanese find $18.1 \%$; Zhu et al. (2020) in 836 Chinese find 20.8\%; Pieh et al. (2020) in 1005 Austrian find 21\%; Shevlin et al. (2020) in 2025 UK respondents finds $22.1 \%$; Liu et al. (2020) in 14592 Chinese population finds $24.1 \%$; Mechili et al. (2020) in 281 Albanians find 25.4\%; Šljivo et al. (2020) in general population of Bosnia and Herzegovina finds 28.4\% and Jia et al. (2020) in 3097 British respondents finds $31.6 \%$. The only PHQ-2 study by GonzálezSanguino et al. (2020) found $18.7 \%$ depression in the Spanish population.

The first case with COVID-19 in Kosovo was identified on 13 March 2020 and three days later a Public Health Emergency was announced with strict lockdown restrictions put in place. In the period when data were collected for this study 27.04.-05.06.2020 we have an increase in the number of infected from 780 reaches 1158 and deaths from 22 to 30 (Kosovo's population is about 1.8 million inhabitants). This marks a period when the phase of relief begins after very restrictive initial restrictions. 
Faced with the pandemic in Kosovo, the provision of essential mental health services to the population in the form of home visits, emergency psychiatric visits, telephone lines of psychological assistance, etc. has continued. The Prizren Mental Health Center continued to offer ICBT online therapy as part of the Implemental project, funded by European Commission, Horizon 2020 framework. In order to support the wider population the online platform IFightDepression was also offered through the un-giuded version.

After the war, Kosovo, like many other post-war societies, is experiencing many challenges, including economic stagnation, widespread poverty, high unemployment, the movement of population from rural to urban areas, and poor quality of life, according to many agency reports. There are few studies conducted in Kosovo that provide data on depression levels. These studies are not very relevant to our work. Arënliu et al (2016) analyzing data from the European Social Survey, Sixth Round (ESS-6) through the CES$\mathrm{D}$ questionnaire finds higher average for depressive symptoms in the Kosovar population than the average reported in other European countries, but similar to those in Eastern European countries. Males had lover significant values than females. Shahini et al. (2019) on 373 adults (247 war veterans and 126 women of other war veterans), through the Adult Self Report (ASR) questionnaire finds that the prevalence of the Anxious / depressive subscale in the deviant range resulted in $4.8 \%$ of males and $4 \%$ of females, in the subscale of withdrawal / depression $7.2 \%$ of males and $9.6 \%$ of females, without any significant gender difference; comparable to those found in other countries. Studying the sample of 249 respondents (17-70 years old, $\mathrm{M}_{\text {age }}=36.6$ ) of the general population of the Drenica region, Fanaj et al. (2014) found depression at the clinical level in $10.7 \%$.

The aim of this study is to understand the presence of depression in general population as a result of the situation created by COVID-19, possible associations with sociodemographic variables and expectations regarding the psychotherapy offered / supported on the Internet. To our knowledge, this is among the first researches in Kosovo in the field of mental health in the current situation with Covid-19.

\section{SUBJECTS AND METHODS}

A cross-sectional design was utilized and a snowball recruitment strategy was applied. Participants were recruited through a web-based survey disseminated through several online channels including Facebook (OS Psikiatri page). Facebook is increasingly being used as an effective research recruitment strategy (Thornton et al. 2016, Koenings et al. 2014) with support that online administration of questionnaires results in acceptable reliability of responses (Carlbring et al. 2007, Garb 2007). Participants gave online consent that their participation was voluntary, confidential and unidentifiable. The questionnaire was delivered through Google Forms where the responses were collected. The data were processed from the responses received in the period of 40 days (27.04.-05.06.2020) after the announcement in the media. Socio-demographic information was obtained regarding age, gender, place of residence, marital status, employment status, socioeconomic status, level of education, previous diagnosis and treatment of any mental illness or depression, and expectations regarding ICBT. Participants also completed the Albanian version of PHQ-9 translated and back-translated by the co-authors of this paper. The PHQ-9 scale is a self-reporting tool designed to measure nine depressive symptoms based on the DSM-IV diagnostic criteria that occurred in the past 2 weeks. The responses were summed to total score ranging from 0 to 27 . Based on previous guidance (Kroenke et al. 2010), depressive symptoms were classified by severity, into minimal (scores of 0-4), mild (5-9), moderate (10-14), moderately severe and severe (15-27). Martin et al. (2009) concluded that PHQ-9 seems to be a useful tool to recognize subthreshold depressive disorder in the general population (see also Wang et al. 2014; Shin et al. 2020). Psychometric properties for the PHQ-9 have been shown to be good, with an internal consistency in the Cronbach's range alpha $=0.86-0.89$ and a test-retest reliability of $\mathrm{r}=0.84$ (24); also Kocalevent et al. (2013) in the general population has found that Cronbach's $\alpha$ for the PHQ-9 scale reached the value of $\alpha=0.87$ and Rief et al. (2004) $\alpha=0.89$. Cronbach alpha was used to assess the internal consistency of the PHQ-9, and an alpha value of $>0.8$ was considered a criterion of good reliability in this study. Approval for research was obtained from the Ethical-Professional Committee of the University Clinical Hospital Service of Kosovo, no. 836, dated 05.05.2020. Data processing was performed with SPSS 21.0 and Microsoft Excel 2007.

\section{RESULTS}

The participants were 155 respondents (117 females, 38 males). Respondents were between 15 and 58 years old with average age of 24.49 years $(\mathrm{SD}=9.22)$.

Mean overall score of depression was 10.94 $(\mathrm{SD}=9.22), 12.03$ for women and 7.6 for men. Moderate to severe symptoms of depression were reported by $35.6 \%$ of the participants and $18.7 \%$ had mild symptoms. Most of participants $(90.2 \%)$ had not been previously treated for any mental health problem other than depression, $16.3 \%$ had been previously diagnosed with depression and $8.6 \%$ had received treatment for depression. Sixty-three percent of the participants agreed that COVID-19 situation has worsened their psychological state. A limited proportion of participants thought that iCBT can be helpful ranging from $13.4 \%$ who thought it can be helpful to $16.8 \%$ who reported that it may be a little helpful. However, $65.8 \%$ of the participants stated that they would want to try it iCBT (Table 1). 
Table 1. Demographic characteristics of the participants $(\mathrm{n}=155)$ in the survey

\begin{tabular}{|c|c|c|c|c|}
\hline & $\mathrm{N}$ & $\%$ & Mean & $\mathrm{SD}$ \\
\hline \multicolumn{5}{|l|}{ Gender } \\
\hline Male & 38 & 24.5 & 7.61 & 7.77 \\
\hline Female & 117 & 75.5 & 12.03 & 7.59 \\
\hline \multicolumn{5}{|l|}{ Resdence } \\
\hline Urban & 100 & 64.5 & 10.84 & 7.67 \\
\hline Rural & 54 & 34.8 & 10.96 & 8.22 \\
\hline Missing & 1 & 0.6 & & \\
\hline \multicolumn{5}{|l|}{ Age group } \\
\hline 14 to 17 years old & 26 & 16.8 & 8.19 & 7.16 \\
\hline 18 to 24 years old & 74 & 47.7 & 13.18 & 7.64 \\
\hline 25 to 34 years old & 27 & 17.4 & 7.19 & 7.62 \\
\hline 35 to 44 years old & 12 & 7.7 & 9.00 & 8.21 \\
\hline 45 to 54 years old & 4 & 2.6 & 11.25 & 4.99 \\
\hline 55 to 64 years old & 4 & 2.6 & 11.75 & 6.55 \\
\hline Over 65 years old & 0 & 0 & & \\
\hline \multicolumn{5}{|l|}{ Education } \\
\hline Primary & 9 & 5.8 & 13.33 & 10.61 \\
\hline Secondary & 79 & 51.0 & 10.73 & 7.63 \\
\hline Bachelor & 56 & 36.1 & 11.77 & 7.87 \\
\hline Master & 10 & 6.5 & 6.90 & 5.34 \\
\hline Doctoral & 1 & 0.6 & & \\
\hline \multicolumn{5}{|l|}{ Marita status } \\
\hline Not married & 107 & 69.0 & 10.93 & 8.06 \\
\hline Married & 38 & 24.5 & 11.92 & 7.44 \\
\hline Separated & 2 & 1.3 & 3.50 & 3.54 \\
\hline Widowhood & 4 & 2.6 & 12.25 & 7.59 \\
\hline Missing & 4 & 2.6 & & \\
\hline \multicolumn{5}{|l|}{ Economic situation } \\
\hline Poor & 14 & 9.0 & 14.64 & 5.21 \\
\hline Middle & 97 & 62.6 & 10.49 & 7.70 \\
\hline Good & 44 & 28.4 & 10.74 & 8.67 \\
\hline \multicolumn{5}{|l|}{ Employment } \\
\hline No & 103 & 66.5 & 11.29 & 7.79 \\
\hline Sesonal & 15 & 9.7 & 11.07 & 7.99 \\
\hline Yes & 37 & 23.9 & 9.92 & 8.08 \\
\hline
\end{tabular}

Previous treatment for mental health problems others than depression

$\begin{array}{lrrrr}\text { No } & 138 & 89.0 & 10.51 & 7.71 \\ \text { Yes } & 15 & 9.7 & 15.13 & 8.64 \\ \text { Previously diagnosed with depression } & & & \\ \text { No } & 128 & 82.6 & 10.18 & 7.60 \\ \text { Yes } & 25 & 16.1 & 14.96 & 8.31 \\ \text { Previously treated with depression } & & & \\ \quad \text { No } & 139 & 89.7 & 10.37 & 7.52 \\ \quad \text { Yes } & 13 & 8.4 & 15.23 & 9.52 \\ \text { Type of treatment taken } & & & & \\ \quad \text { Medicaments } & 40 & 25.8 & 11.13 & 8.02 \\ \text { Psychotherapy } & 12 & 7.7 & 11.42 & 8.92 \\ \text { Medicaments and psychotherapy } & 6 & 3.9 & 15.67 & 10.17\end{array}$

Perception of worsened psychological state

from COVID-19 situation

$\begin{array}{lllll}\text { No } & 55 & 35.5 & 6.71 & 7.01\end{array}$

$\begin{array}{lllll}\text { Yes } & 96 & 61.9 & 13.33 & 7.35\end{array}$

Expectations for help from e-psychotherapy

$\begin{array}{lllll}\text { I don't believe it helps me } & 6 & 3.9 & 9.50 & 8.46\end{array}$

$\begin{array}{lllll}\text { I don't know, to try it } & 98 & 63.2 & 10.91 & 7.75\end{array}$

$\begin{array}{lllrr}\text { It can help me a little } & 25 & 16.1 & 8.84 & 7.86\end{array}$

It can help me a lot $\quad \begin{array}{llll}20 & 12.9 & 14.70 & 8.05\end{array}$

Depression

No depresion

Minimal symptoms

Mild Depression

Medium Depression

Severe Depression
Mann-Whitney test revealed significant gender differences of depression scores $\left(\mathrm{Md}_{\text {females }}=12, \mathrm{~N}=116\right.$; $\left.\mathrm{Md}_{\text {males }}=3.5, \mathrm{~N}=38 ; \mathrm{Z}=-3.239, \mathrm{p}<0.00\right)$. Significant difference has also resulted for both somatic $\left(\mathrm{Md}_{\text {females }}=5\right.$, $\left.\mathrm{N}=117 ; \mathrm{Md}_{\text {males }}=2.5, \mathrm{~N}=38 ; \mathrm{Z}=-2.554, \mathrm{p}<0.01\right)$ and cognitive / affective $\left(\mathrm{Md}_{\text {females }}=6, \mathrm{~N}=116 ; \mathrm{Md}_{\text {males }}=3\right.$, $\mathrm{N}=38 ; \mathrm{Z}=-2.958, \mathrm{p}<0.00)$ subscales.

We found significant difference in depression levels between those who were previously treated for any mental health problems other than depression or not $\left(\mathrm{Md}_{\text {treatmhyes }}=16, \mathrm{~N}=15 ; \mathrm{Md}_{\text {treatmhno }}=10, \mathrm{~N}=137 ; \mathrm{Z}=-1.977\right.$, $\mathrm{p}<0.04)$. There is a significant difference in that those who were diagnosed with depression had higher levels of depression $\left(\mathrm{Md}_{\text {dgyes }}=17, \mathrm{~N}=25 ; \mathrm{Md}_{\mathrm{dgno}}=10, \mathrm{~N}=127\right.$; $\mathrm{Z}=-2.644, \mathrm{p}<0.00)$. There is a significant difference in that those who had been treated before for depression had higher levels of depression $\left(\mathrm{Md}_{\text {treatdyes }}=18, \mathrm{~N}=13\right.$; $\left.\mathrm{Md}_{\text {treatdno }}=10, \mathrm{~N}=138 ; \mathrm{Z}=-1.977, \mathrm{p}<0.04\right)$. There is also a significant difference in that those who agreed that the situation with COVID-19 had worsened their psychological state had higher levels of depression $\left(\mathrm{Md}_{\mathrm{yes}}=14\right.$, $\left.\mathrm{N}=96 ; \mathrm{Md}_{\mathrm{no}}=4, \mathrm{~N}=55 ; \mathrm{Z}=-5.024, \mathrm{p}<0.00\right)$.

Kruskal-Wallis analysis doesn't reveal significant differences by levels of education, marital status, employment status, socio-economic status and by expectations regarding iCBT. The only significant difference is found by age-group $\mathrm{X} 2(5, \mathrm{n}=146)=17.141, \mathrm{p}<0.00$; whereas group of respondents 18 to 24 years $(\mathrm{Md}=14)$ had the significantly highest depressive scores as compared to age-group 45 to 54 years and 55 to 64 years $(\mathrm{Md}=11.5)$ and 35 to 44 years $(\mathrm{Md}=6)$.

Regarding response items female resulted with higher scores in all items but significantly only for depressed mood, low energy, low self-esteem, concentration difficulties and suicidal ideation (Table 2).

A multiple standard regression analysis was run to predict depression from gender, age, education, marital status, employment, socio-economic status, previous treatment for mental health problems, previously diagnosed with depression, previously treated with depression, perception of worsened psychological state from COVID-19 situation and expectations for help from e-psychotherapy. These variables statistically significantly predicted depression, $\mathrm{F}(11,142)=4.185, \mathrm{p}<0.000, \mathrm{R} 2=0.260$. Only gender and perception of worsened psychological state from covid-19 situation added statistically significantly to the prediction, $\mathrm{p}<0.00$ (Table 3 ).

\section{DISCUSSION}

Findings that $61.9 \%$ of the participants agreed that COVID-19 situation has worsened their psychological state, is higher than reports in Italy - 38\% (Moccia et al. 2020); Spain - 31\% (Odriozola-González et al. 2020) and China - 35\% (Qiu et al. 2020); but similar to Iran (61.1\%; Jahanshahi et al. 2020) and Bangladesh $59.7 \%$ (Al Banna et al. 2020). The finding that $35.6 \%$ of the participants reported depression symptoms ranging from moderate to severe (cut-off point 10 and more), 
Table 2. Percentages of PHQ-9 item responses, mean and gender significances of the participants in the survey

\begin{tabular}{|c|c|c|c|c|c|}
\hline Item response & $\begin{array}{c}0 \text { (not at all) }+1 \\
(\text { several days })\end{array}$ & $\begin{array}{c}2 \text { (more than half } \\
\text { the days) }\end{array}$ & $\begin{array}{c}3 \text { (nearly every } \\
\text { day) }\end{array}$ & Mean & $\begin{array}{c}\text { Gender/ Sig. } \\
\mathrm{p}\end{array}$ \\
\hline Depressed mood & $41.9 \%$ & $14.8 \%$ & $43.8 \%$ & 1.59 & 0.012 \\
\hline Sleep problems & $51.0 \%$ & $15.5 \mathrm{v}$ & $33.5 \%$ & 1.31 & 0.116 \\
\hline Low energy & $43.2 \%$ & $20.0 \%$ & $36.8 \%$ & 1.50 & 0.001 \\
\hline Low self-esteem & $53.5 \%$ & $14.2 \%$ & $32.3 \%$ & 1.25 & 0.030 \\
\hline Concentration difficulties & $57.6 \%$ & $15.7 \%$ & $26.8 \%$ & 1.08 & 0.001 \\
\hline Appetite change & $56.7 \%$ & $18.7 \%$ & $24.5 \%$ & 1.11 & 0.233 \\
\hline Psychomotor agitation or retardation & $54.8 \%$ & $17.4 \%$ & $27.7 \%$ & 1.18 & 0.285 \\
\hline Anhedonia & $62.5 \%$ & $12.3 \%$ & $25.2 \%$ & 1.00 & 0.860 \\
\hline Suicidal ideation & $76.0 \%$ & $5.8 \%$ & $18.2 \%$ & 0.84 & 0.018 \\
\hline
\end{tabular}

Table 3. Multiple Regression Analysis Summary for variables and Depression (PHQ-9)

\begin{tabular}{lrcc}
\hline Variable & B & SEB & Beta \\
\hline Age & -0.912 & 0.709 & -0.130 \\
Gender & 3.459 & 1.486 & $0.190^{*}$ \\
Education & 0.782 & 1.337 & 0.048 \\
Marital status & -0.896 & 0.855 & -0.084 \\
Socio-economic status & 0.535 & 1.079 & 0.044 \\
Employment & -1.177 & 1.085 & -0.087 \\
Previous treatment for mental health problems others than depression & 0.238 & 0.785 & 0.026 \\
Previously diagnosed with depression & 1.935 & 2.289 & 0.074 \\
Previously treated with depression & 2.865 & 1.968 & 0.135 \\
Perception of worsened psychological state from COVID-19 situation & 0.540 & 2.737 & $0.019^{*}$ \\
Expectations for help from e-psychotherapy & 5.874 & 1.295 & 0.361 \\
Constant & 5.980 & 4.780 & \\
\hline
\end{tabular}

indicates a high level of depression in this sample, considering the average lifetime and 12-month prevalence estimates of major depression were $14.6 \%$ and $5.5 \%$ in high-income countries and $11.1 \%$ and $5.9 \%$ in low- to middle-income countries (Bromet et al. 2011). Also these findings are higher compared to studies in general populations in other countries that have used PHQ-9 which has resulted in moderate to severe (cut-off point 10 and more) of 3.8 to $8.8 \%$ (Shinn et al. 2020; Kocalevent et al. 2013; Rief et al. 2004). Also, the high level of depression in this study is evident when comparing our results with the few depression studies in Kosovo (with other questionnaires) that show depression at the clinical level is $10.7 \%$ (Fanaj et al. 2014) and in a sample of war veterans about $7 \%$ (Shahini et al. 2019). Hovewer, one study in Kosova has reported nearly prevalence of depression (27\%; cutoff $>10)$, but this is conducted in a small sample of primary care patients not general population (Ajredini et al. 2019). Our findings are slightly higher compared to the study in Albania 25.2\% / 25.6\%, which also used PHQ-9 (Mechili et al. 2020) and to the study in general population of Bosnia and Herzegovina 28.4\% (Śljivo et al. 2020) as well as the all other studies cited here who scored 17.3 to $31.6 \%$. It is clear that the population is suffering psychologically as studies (Xiang et al. 2020, Kang et al. 2020) show. Finding that women are significantly more affected by depression is in line with many studies (Rossi et al. 2020, Mazza et al. 2020, Wang et al. 2020, Šljivo et al. 2020). The findings that those with previous treatment for mental health problems, those who were diagnosed, those who had been treated before had higher levels of depression indicates that the situation caused by Covid-19 may be exacerbating the condition of people with pre-existing disorders (Yao et al. 2020) and people with a psychological disorder (Karaşar et al. 2020). It is interesting to note that respondents 18 to 24 years have significantly higher levels of depression. This is in line with findings of other studies (Rossi et al. 2020, Shevlin et al. 2020, Huang \& Zhao 2020, Šljivo et al. 2020). There have been findings earlier that perhaps young people more easily activate stress due to their greater access to information through social media (Cheng et al. 2014), which undoubtedly in this time period has been very bad (increase in the number of infected and deaths). Other factors could be restrictive measures, interruption of schooling, etc. In 2017, an exploratory study in Kosovo (Fanaj et al. 2017) found that $17.5 \%$ of the sample expected e-psychotherapy to be beneficial and 57.8\% considered it may be beneficial. In this study we have an increase in expectations because $29 \%$ saw it as somehow helpful and $63.2 \%$ were willing to try it; we see this as particularly positive given that depression causes feelings of hopelessness and negatively impacts help-seeking behavior. This may also be in line with the suggestions that it is the right moment for a shift towards online prevention, treatment, and care (Wind et al. 2020). Findings that there are no significant differences in the levels of depression according to marital status, employment and 
socio-economic status can be explained in part by the fact that we are dealing here more with a reactive depression by the situation that the population is going through, even also literature findings are inconsistent in this regard. Findings that only gender and perception of worsened psychological state from covid-19 situation added statistically significantly to the prediction can be explained by the well-known fact that the female gender is more sensitive and by the fact that the level of distress experienced by the Covid-19 pandemic is clearly causing depression.

\section{Limitations}

We should mention here some limitations of this study. Undoubtedly, the cross-sectional nature of the research, then the use of Facebook for recruitment can bring obstacles to having a representative sample because of the inability to access the Internet or social networks (elderly, low socioeconomic cases, psychiatric patients etc.). Also, self-reporting without the possibility of an objective assessment by professionals can be listed here.

\section{CONCLUSIONS}

Worsening of psychological condition and high levels of depression speak about the high level of mental health problems in Kosovo as a result of COVID-19 pandemic, especially in youths. These should be addressed as appropriately and timely as possible. There is need for continuing with services such as internet psychotherapy as a worth to try solution. However, more indepth studies are needed which will shed more light on this period of pandemic coping.

\section{Acknowledgments:}

\section{Ethical considerations}

Approval for research was obtained from the EthicalProfessional Committee of the University Clinical Hospital Service of Kosovo, no. 836, dated 05.05.2020.

\section{Conflict of interest: None to declare.}

\section{Contribution of individual authors:}

Naim Fanaj was the principal investigator. However, the first and second authors contributed to the study design, analysis and interpretation of data, and drafting the manuscript.

Sevim Mustafa contributed to the study design, analysis and interpretation of data, and drafting the manuscript.

\section{References}

1. Ajredini A, Brina-Hashani F, Fanaj N: Skriningu për depresionin/suicidalitetin në Kujdesin Parësor në Prizren. Paper presented at: Konferenca Kombëtare për Ditën Botërore të Shëndetit Mendor-Vetëvrasjet mund të parandalohen; October 14, 2019; Vërmicë-Prizren, Kosovo. Available at https://qshm-pz.com/fletepalosja-e- konferenca-kombetare-per-diten-boterore-te-shendetitmendor-parandalimi-i-vetevrasjeve-vermice-prizren-14tetor-2019\%. Accessed December 3, 2020

2. Al Banna MH, Sayeed A, Kundu S, Christopher E, Hasan MT, Begum MR et al:. The impact of the COVID-19 pandemic on the mental health of the adult population in Bangladesh: A nationwide cross-sectional study. PsyArXiv 2020; doi:10.1080/09603123.2020.1802409

3. Arenliu A, Kelmendi K, Berxulli D: Gender differences in depression symptoms: Findings from a population survey in Kosovo-A country in transition. Psychol Thought 2016; 9: 236-47

4. Bromet E, et al. Cross-national epidemiology of DSM-IV major depressive episode. BMC med 2011; 9:90.

5. Carlbring P, Brunt S, Bohman S, Austin D, Richards J, Öst $L G$ et al: Internet vs. paper and pencil administration of questionnaires commonly used in panic/agoraphobia research. Comput Hum Behav 2007; 23:1421-34

6. Cheng C, Jun H, Liang B: Psychological health diathesis assessment system: A nationwide survey of resilient trait scale for Chinese adults. Stud Psychol Behav 2014; 12:735-742

7. Fanaj N, Cerga-Pashoja A, Morina F, Mustafa S, Gashi $A$, Bojaj et al: Exploratory, cross-sectional survey on public perceptions of e-psychotherapy in Kosovo. Paper presented at: ISRII 9th Scientific Meeting; 12-14 October 2017; Berlin, Germany

8. Fanaj N, Halilaj G, Melonashi E, Drevinja F, Dana Xh, Poniku I et al: PTSD, Depression and Quality of Life in Post-War Kosovo. Eur Psychiatry 2014; 29-1. doi:10.1016/S0924-9338(14)77859-9

9. Garb HN. Computer-administered interviews and rating scales. Psychol Assess 2007; 19:4

10. González-Sanguino C, Ausín B, ÁngelCastellanos M, Saiz $J$, López-Gómez A, Ugidos C et al: Mental health consequences during the initial stage of the 2020 Coronavirus pandemic (COVID-19) in Spain. Brain Behav Immun 2020; 87:172-176

11. Holmes EA, O'Connor RC, Perry VH, Tracey I, Wessely S, Arseneault $L$ et al: Multidisciplinary research priorities for the COVID-19 pandemic: a call for action for mental health science. Lancet Psychiatry 2020; 7:547-560

12. Huang Y, Zhao N: Generalized anxiety disorder, depressive symptoms and sleep quality during COVID-19 outbreak in China: a web-based cross-sectional survey. Psychiatry Res 2020; 228:112954

13. Jahanshahi AA, Dinani MM, Madavani AN, Li J, Zhang SX: The distress of Iranian adults during the Covid-19 pandemic - More distressed than the Chinese and with different predictors. Brain Behav Immun 2020; 87:124-125

14. Jia R, Ayling $K$, Chalder T, Massey A, Broadbent E, Coupland $C$ et al: Mental health in the UK during the COVID-19 pandemic: early observations. medRxiv 2020; doi:10.1101/2020.05.14.20102012

15. Kang L, Li Y, Hu S, Chen M, Yang C, Yang BX et al: The mental health of medical workers in Wuhan, China dealing with the 2019 novel coronavirus. Lancet Psychiatry 2020; 7:e14

16. Karaşar B, Canlı D: Psychological resilience and depression during the Covid-19 pandemic in Turkey. Psychiatr Danub 2020; 32:273-9

17. Kocalevent RD, Hinz A, Brähler E. Standardization of the depression screener patient health questionnaire (PHQ-9) in the general population. Gen Hosp Psychiatry 2013; 35:551-555 
18. Koenings M, Martin-Biggers J, Byrd-Bredbenner C. Recruiting RCT participants: to Facebook or not to Facebook?. The FASEB J 2015; 29:584-2

19. Kroenke K, Spitzer RL, Williams JB, Löwe B. The patient health questionnaire somatic, anxiety, and depressive symptom scales: a systematic review. Gen Hosp Psychiatry 2010; 32: 345-359

20. Liu D, Ren Y, Yan F, Li Y, Xu X, Yu X et al: Psychological Impact and Predisposing Factors of the Coronavirus Disease 2019 (COVID-19) Pandemic on General Public in China. (3/7/2020). Available at SSRN: http://dx.doi.org/ 10.2139/ssrn.3551415. Accessed December 3, 2020

21. Martin A, Rief W, Klaiberg A, Braehler E. Validity of the brief patient health questionnaire mood scale (PHQ-9) in the general population. Gen Hosp Psychiatry 2006; 28:71-77

22. Mazza C, Ricci E, Biondi S, Colasanti M, Ferracuti S, Napoli $C$ et al: A nationwide survey of psychological distress among Italian people during the COVID-19 pandemic: Immediate psychological responses and associated factors. Int J Environ Res Public Health 2020; 17:3165

23. Mechili EA, Saliaj A, Kamberi F, Girvalaki C, Peto E, Patelarou AE et al: Is the mental health of young students and their family members affected during the quarantine period? Evidence from the COVID-19 pandemic in Albania. J Psychiatr Ment Health Nurs; 00:1-9

24. Moccia L, Janiri D, Pepe M, Dattoli L, Molinaro M, De Martin V et al: Affective temperament, attachment style, and the psychological impact of the COVID-19 outbreak: an early report on the Italian general population. Brain Behav Immun 2020; 87: 75-79

25. Odriozola-González P, Planchuelo-Gómez Á, Irurtia-Muñiz $M J$, de Luis-Garcia R. Psychological symptoms of the outbreak of the COVID-19 crisis and confinement in the population of Spain. PsyArXiv 2020. doi:10.1177/1359105320967086

26. Panchal N, Kamal R, Orgera K, Cox C, Garfield R, Hamel $L$ et al: The implications of COVID-19 for mental health and substance use. Kaiser Family Foundation 2020. Available at https://abtcounseling.com/wp-content/uploads/2020/ 09/The-Implications-of-COVID-19-for-Mental-Health-andSubstance-Use-_KFF.pdf. Accessed December 3, 2020

27. Pieh C, Budimir S, Probst T: The effect of age, gender, income, work, and physical activity on mental health during coronavirus disease (COVID-19) lockdown in Austria. J Psychosom Res 2020; 136:110186

28. Qiu J, Shen B, Zhao M, Wang Z, Xie B, Xu Y: A nationwide survey of psychological distress among Chinese people in the COVID-19 epidemic: implications and policy recommendations. Gen psychiatry 2020; 33:e100213

29. Rief W, Nanke A, Klaiberg A, Braehler E. Base rates for panic and depression according to the Brief Patient Health Questionnaire: a population-based study. J Affect Disord 2004; 82:271-276

30. Rossi R, Socci V, Talevi D, Mensi S, Niolu C, Pacitti F et al: COVID-19 pandemic and lockdown measures impact on mental health among the general population in Italy. Front Psych 2020; 11:790
31. Shahini M, Rescorla LA, Shala M, Ukshini S: Living on the Edge: Emotional and Behavioral Problems in a Sample of Kosovar Veterans and Wives of Veterans 16 Years Postwar. Front Psychiatry 2019; 10: 598

32. Shevlin M, Nolan E, Owczarek M, McBride O, Murphy J, Gibson Miller J et al: COVID-19- related anxiety predicts somatic symptoms in the UK population. Br J Health Psychol: 2020; 25:875-882.

33. Shin C, Ko YH, An H, Yoon HK, Han C: Normative data and psychometric properties of the Patient Health Questionnaire-9 in a nationally representative Korean population. BMC psychiatry 2020; 20:1-0

34. Sønderskov KM, Dinesen PT, Santini ZI, Østergaard SD: The depressive state of Denmark during the COVID-19 pandemic. Acta neuropsychiatry 2020; 32:226-228

35. Šljivo A, Kačamaković M, Quraishi I, Džubur Kulenović A: Fear and depression among residents of Bosnia And Herzegovina during COVID-19 outbreak-internet survey. Psychiatr Danub 2020; 32:266-72

36. Thornton L, Batterham PJ, Fassnacht DB, Kay-Lambkin F, Calear AL, Hunt S. Recruiting for health, medical or psychosocial research using Facebook: Systematic review. Intern Interv 2016; 4:72-81

37. Ueda M, Stickley A, Sueki H, Matsubayashi T: Mental Health Status of the General Population during the COVID19 Pandemic: A Cross-sectional National Survey in Japan. medRxiv 2020; doi:10.1101/2020.04.28.20082453

38. Wang C, Pan R, Wan X, Tan Y, Xu L, Ho CS et al: Immediate psychological responses and associated factors during the initial stage of the 2019 coronavirus disease (COVID-19) epidemic among the general population in China. Int J Environ Res Public Health 2020; 17:1729

39. Wang $W$, Bian $Q$, Zhao $Y$, Li X, Wang $W$, Du J et al: Reliability and validity of the Chinese version of the Patient Health Questionnaire (PHQ-9) in the general population. et al: Gen Hosp Psychiatry 2014; 36:539-544

40. Wang Y, Di Y, Ye J, Wei W: Study on the public psychological states and its related factors during the outbreak of coronavirus disease 2019 (COVID-19) in some regions of China. Psychol Health Medicine 2020. doi: 10.1080/13548506.2020.1746817

41. Wind TR, Rijkeboer M, Andersson G, Riper H: The COVID19 pandemic: The 'black swan'for mental health care and a turning point for e-health. Internet Interv 2020; 20: 100317

42.WHO: Mental health and psychosocial considerations during the COVID-19 outbreak, 18 March 2020. World Health Organization 2020

43. Xiang YT, Yang Y, Li W, Zhang L, Zhang Q, Cheung T et al: Timely mental health care for the 2019 novel coronavirus outbreak is urgently needed. Lancet Psychiatry 2020; 7:228-229

44. Yao H, Chen JH, Xu YF: Patients with mental health disorders in the COVID-19 epidemic. Lancet Psychiatry 2020; 7:e21

45. Zhu S, Wu Y, Zhu CY, Hong WC, Yu ZX, Chen ZK et al: The immediate mental health impacts of the COVID-19 pandemic among people with or without quarantine managements. Brain Behav Immun 2020; 87:56-58

\section{Correspondence:}

Naim Fanaj, MD

Mental Health Center Prizren

Str. Xhevat Berisha, n.n., 20000, Prizren, Kosovo

E-mail:naimfanaj@gmail.com 